\title{
What are key determinants of hospital admissions, re-admission rate and day case rate within the South African medical schemes population?
}

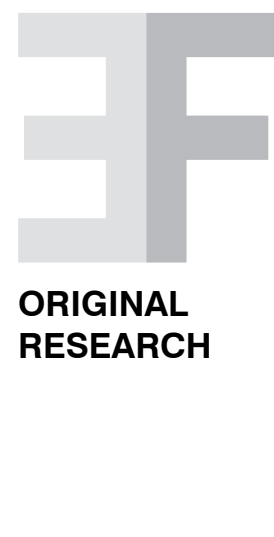

\author{
Nondumiso Gugu Khumalo ${ }^{1}$, Michael Willie ${ }^{1}$, Evelyn Thsehla \\ Research and Monitoring Unit, Council for Medical Schemes, South Africa
}

\begin{abstract}
BACKGROUND: In South Africa, private hospitals absorb a high proportion of the total health expenditure on private health care. Between 2008-2010 private hospital expenditure which includes ward fees, theatre fees, consumables, medicines and per diem arrangements consumed between $40.5 \%$ and $40.9 \%$ of the total benefits paid by medical schemes from the risk pool, whilst in-hospital managed care fees ranged between $1.8 \%$ and $2.8 \%$ for the equivalent years.

OBJECTIVE: The aim of this paper is to highlight key factors contributing to utilisation of hospital services within the medical schemes population and to recommend "appropriate" and cost effective strategies on hospital utilisation management. METHODS: A cross sectional survey informed by retrospective analysis of quantitative data was used. Researchers also triangulated quantitative data with systematic review of literature.

RESULTS: The results show that demographic indicators such as age profile, dependency ratio, pensioner ratio and prevalence of chronic conditions are not the only key factors influencing hospital admissions, but rather the effectiveness of each medical scheme in containing hospital admissions is also influenced by available technical capacity on utilisation review and audit as well as the managed care methodology including the philosophy underpinning benefit option design.

CONCLUSION: This study highlights the importance of "value based" managed care programs linked to benefit option design in health care utilisation management. The choice of one managed care program over the other often leads to tradeoffs whereby unintended consequences emanate. Medical schemes are therefore encouraged to continuously review their managed care programs to ensure value for money as well as better access and health outcomes.
\end{abstract}

\section{Keywords}

Health care utilisation; Hospital admission; Re-admission rate; Day case rate; Managed care

\section{BACKGROUND}

A well functioning private health care insurance system does not only promote fair distribution of the burden of paying health services or protect households against the risks of catastrophic health care expenditure; it also reduces barriers to health service use. In South Africa, private health expenditure is mainly financed through medical schemes contributions and out-of-pocket payments. According to National Treasury, the total annual health expenditure by both public and private health care sectors constitutes approximately $8.6 \%$ of the GDP (gross domestic product) and this is a split of between $4.1 \%$ for private sector and $4.2 \%$ in the public sector [1]. Blecher et al. also argued that the $4.1 \%$ spend on private health care covers ap- proximately $17 \%$ of medical schemes population [2].

The GDP of $8.6 \%$ is also not comparable to other countries of similar developmental stages and it does not translate to improved health outcomes within both public and private health care sectors. Furthermore, the Council for Medical Schemes (CMS) observed that high expenditure within private health care is largely influenced by hospital admissions, whereby, between 2008 and 2010, private hospital expenditure - which includes ward fees, theatre fees, consumables, medicines and per diem arrangements - consumed between $40.5 \%$ and $40.9 \%$ of the total benefits paid by medical schemes from the risk pool, whilst total hospital benefits paid from the medical savings accounts ranged between
Corresponding author Dr. Nondumiso Gugu Khumalo n.khumalo@ medicalschemes.com

\section{Disclosure}

The authors declare that they have no competing interest 
$1.5 \%$ and $2.1 \%$. In addition, in-hospital managed care arrangement fees ranged between $1.8 \%$ and $2.8 \%$ for the equivalent years [3]. This observed increase on private health care costs, including hospital services, has lead to an increase in medical schemes contribution rates above Consumer Price Index (CPI) ranging between $9-13 \%$ whilst the CPI ranged between $4 \%$ and $9 \%$ [4]. This implies that over the past years private health care in South Africa has become exorbitantly unaffordable, and this trend has lead to a marginal increase in the total population covered by medical schemes. In light of this context, a study was undertaken to explore factors influencing utilisation of in hospital services and medicine expenditure within the private health care sector. This research project explore determinants of in-hospital admission, length of stay, re-admission rate, day case rates and expenditure on medicine.

\section{AIM}

The aim of this paper is to highlight key factors contributing to utilisation of hospital services and medicine expenditure within the medical schemes population and to recommend "appropriate" and cost effective strategies on hospital and medicine utilisation management.

\section{METHODS}

\section{Conceptual framework}

In order to gain in-depth understanding of factors influencing utilisation of health care services, a socio-behavioural and the Four As models presented below informed development of indicators, data specification tool and analysis of data $[5,6]$. These models, amongst other things, highlight the link between health insurance benefit packages, health seeking behaviour, location of the facility, social networks and socio-cultural factors as important attributes influencing utilisation of health services.

According to Andersen et al. [5], the following factors are important when exploring utilisation of health care services:

- Predisposing factors: age, gender, social capital, ethnicity, educational status, prior experience on illness and health services.

- Enabling factors: availability of services, affordability, health insurance benefit packages and social network support.

- Need factors: perception on severity, days lost due to illness.

- Health services system factors: policy, resources and organisation of the health system.
- Consumer satisfaction: physical, economical and political.

- Personal health practice: diet, exercise and home care (including home treatment).

Hausmann-Muela et al. [6] emphasise the importance of the importance of:

- geographical distribution of health facilities;

- transport, roads and the associated costs;

- direct, in-direct costs associated with accessing health care services;

- socio-cultural factors.

\section{Scope}

The scope of this project was to collect quantitative data to inform key medicine and hospital admission indicators at a medical scheme's level over a period of 2008/2009.

\section{Study design}

This study undertook a descriptive cross sectional survey informed by retrospective review of quantitative data as well as qualitative analysis of medical scheme rules, benefit option reports and actuarial reports. Researchers also triangulated quantitative data with systematic review of literature which resulted in compilation and piloting of 40 health care utilisation measures within the private health care market across different facility types, medical schemes and administrators. These utilisation measures included in-hospital care, out-of-hospital care, specialist care, use of diagnostic technology and expenditure on medicine. The piloting exercise resulted in scaling down on the scope of the project resulting in data collection of only 23 health care utilisation measures. Medical specialists and out-of-hospital care measures were excluded from data collection due to lack of access to specialists and medical schemes beneficiaries for in-depth interviews.

\section{Sampling frame}

A non-random convenient sampling technique was used to select 6 large schemes representing $55 \%$ of lives within the medical schemes population and $13 \%$ of benefit options offered by the medical schemes.

\section{Criterion validity of the selected indicators}

The following parameters were used to inform the criteria for selecting hospital utilisation indicators:

- Simplicity when calculating a combination of indicators to also ensure that participants in the study are not blinded by obscure statistical or mathematical theory [7]. 
- Relevance to the utilisation context within the South African private health care market.

- Scientific soundness of the measure in terms of its validity, reliability, appropriateness and the explicitness of the evidence base.

- Feasibility and availability of data.

The above criteria informed the inclusion and exclusion criteria used for the systematic review of literature and relevant papers were identified using the following approach:

- Database searches and reference snow bowling guided by the study's inclusion and exclusion criteria.

- Consultation with Council for Medical Schemes (CMS) Clinical Committee members as well as medical schemes, administrators, managed health care organisations, private hospital groups and independent health actuaries.

- The definition of each indicator was reviewed to ensure appropriateness (based on the criteria discussed above).

- Utilisation indicators used in other countries were evaluated to ensure comparability and applicability to the South African private health care market.

- Possible data sources were identified for each indicator (Table I).

- All indicators were piloted to improve reliability, validity and responsiveness.

\section{Data analysis}

The following are key steps undertaken when analysing quantitative data:

- Data cleaning to make sure that the collected data was clean and reliable.

- Reviewing completeness and accuracy of data to eliminate errors before analysis.

\begin{tabular}{ll}
\hline \multicolumn{1}{c}{ Data type } & \multicolumn{1}{c}{ Source of data } \\
\hline Beneficiary & ICD10 codes (and relevant diagnosis data) from medical \\
utilisation data & schemes and administrators \\
Hospital & Medical schemes and administrators (ICD10 codes, \\
utilisation data & NHRPL codes and NAPPI codes ) \\
Secondary data & CMS annual reports and 2008/2009 Health Quality \\
& $\begin{array}{l}\text { Assessment (HQA) reports, actuarial reports, medical } \\
\text { schemes rules and benefit option reports }\end{array}$ \\
\hline
\end{tabular}

Table I. Sources of data

- Reviewing of the definition of each indicator including technical criteria/guideline on the analysis and interpretation of observations.

- Producing composed scales to create a single variable from a set of questions and also to make graphics or tables that show relationships.

- Descriptive analysis of data by producing descriptive statistics, such as means, standard-deviations, histograms, etc.

\section{Responder validation}

The observations outlined in this paper were validated against participating medical schemes and administrators as well as compared to HQA reports for the corresponding years. The responder validation process facilitated on ongoing communication with the schemes and administrators on various issues and observations. Researchers were also able to identify missing data; in addition, schemes had an opportunity to review submitted data. Preliminary findings were also presented to all research participants in order to afford each medical scheme an opportunity to engage with the results as well as to contextualise observed trends.

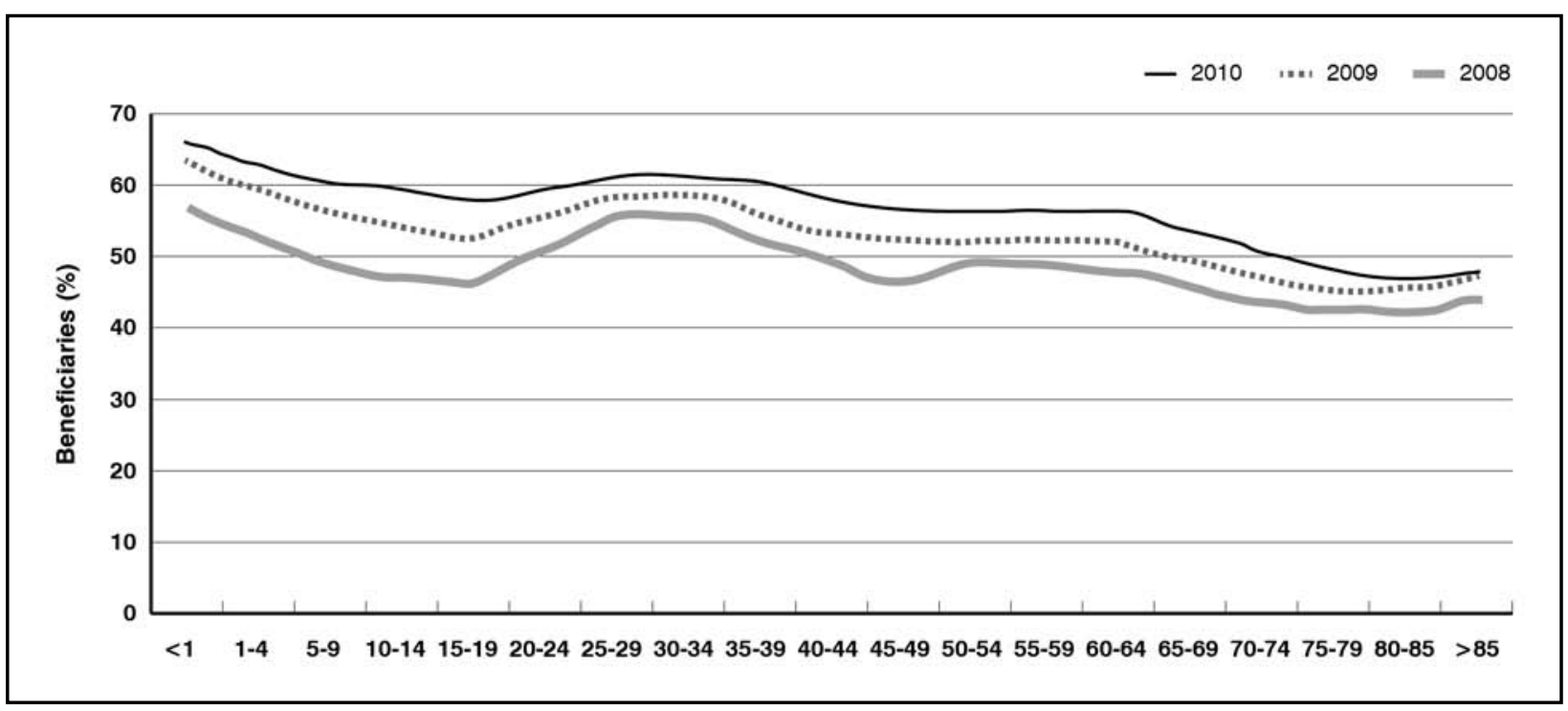

Figure 1. Proportion of sampled beneficiaries by age bands 


\section{RESULTS}

\section{Demographic indicators}

Membership profile - which includes average age, pension's ratio, gender differentiation and dependency ratio - influences the frequency and the claiming profile within each scheme. Average age of the medical scheme population also influence hospital expenditure per beneficiary. For example, older people go to hospital more often than younger people, and once they are admitted, on average they cost more than younger patients during their stay in hospital. Figure 1 portrays a proportion of sampled beneficiaries by age bands from 2008-2010. It was observed that in 2010 membership of the sampled schemes increased by close to $50.9 \%$. Also outlined in the graph the increase in the proportion of beneficiaries is present across all age bands. Figure 2 provides an outline of the average age of beneficiaries within each selected medical schemes. This indicator can influence hospital admission, length of stay, probability of re-admission, use of diagnostic technology as well as medicine expenditure. Noted in the observations is that scheme 3 and scheme 4 appear to have a relatively older profile when compared to other schemes. It would therefore be expected that such scheme would experience a relatively high proportion of hospital admission cases, which was not the case.

Figure 3 illustrates the distribution of pensioner ratio for each scheme. It is important to note that scheme 4 appears to have a relatively high pensioner ratio when compared to

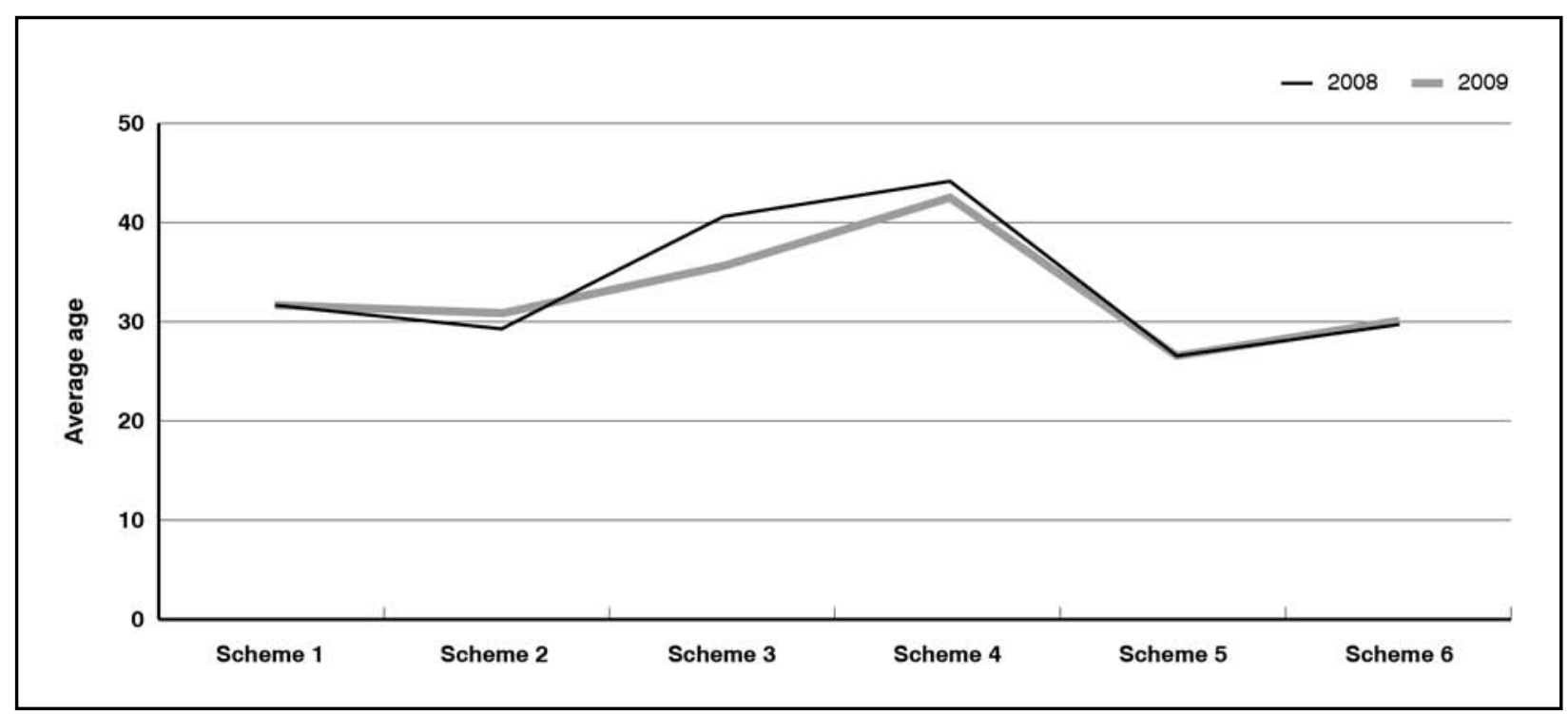

Figure 2. Average age 2008/2009

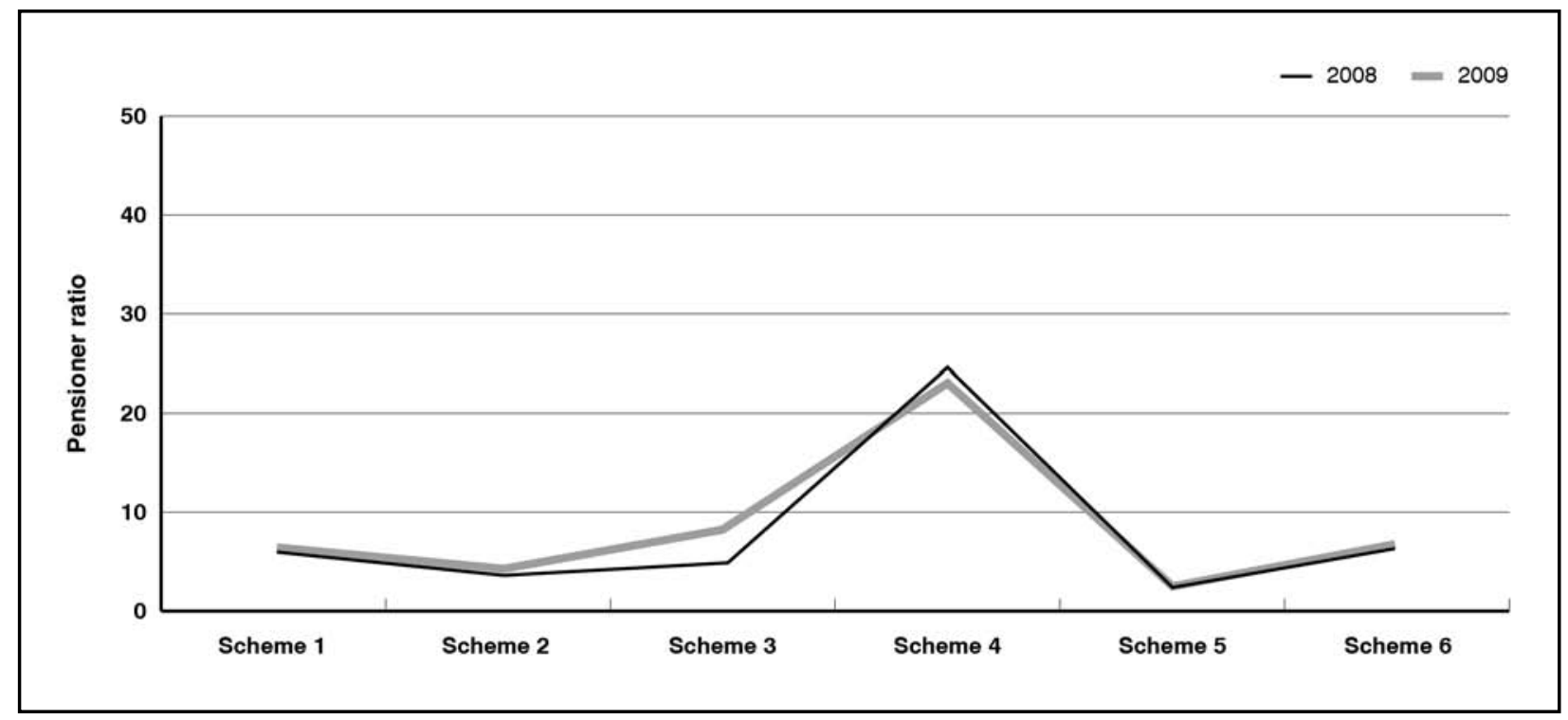

Figure 3. Pensioner ratio for 2008/2009 
all other schemes. In 2009 the proportion of pensioners within the selected schemes was slightly higher compared to 2008 .

\section{Prevalence of chronic conditions}

South Africa is experiencing a quadruple burden of disease; this trend includes AIDS pandemic, high rates of injury, infectious diseases as well as non-communicable diseases (NCDs). According to Medical Research
Council (MRC), NCDs affect a large number of the working-age population, thereby impacting on the workforce and productivity of the country [8]. The major NCDs in South Africa include cardiovascular diseases, diabetes, cancers, chronic respiratory diseases, and mental illness. The national surveillance on the burden of disease suggests that unhealthy lifestyle is one of the key contributing factors to the prevalence of chronic illnesses

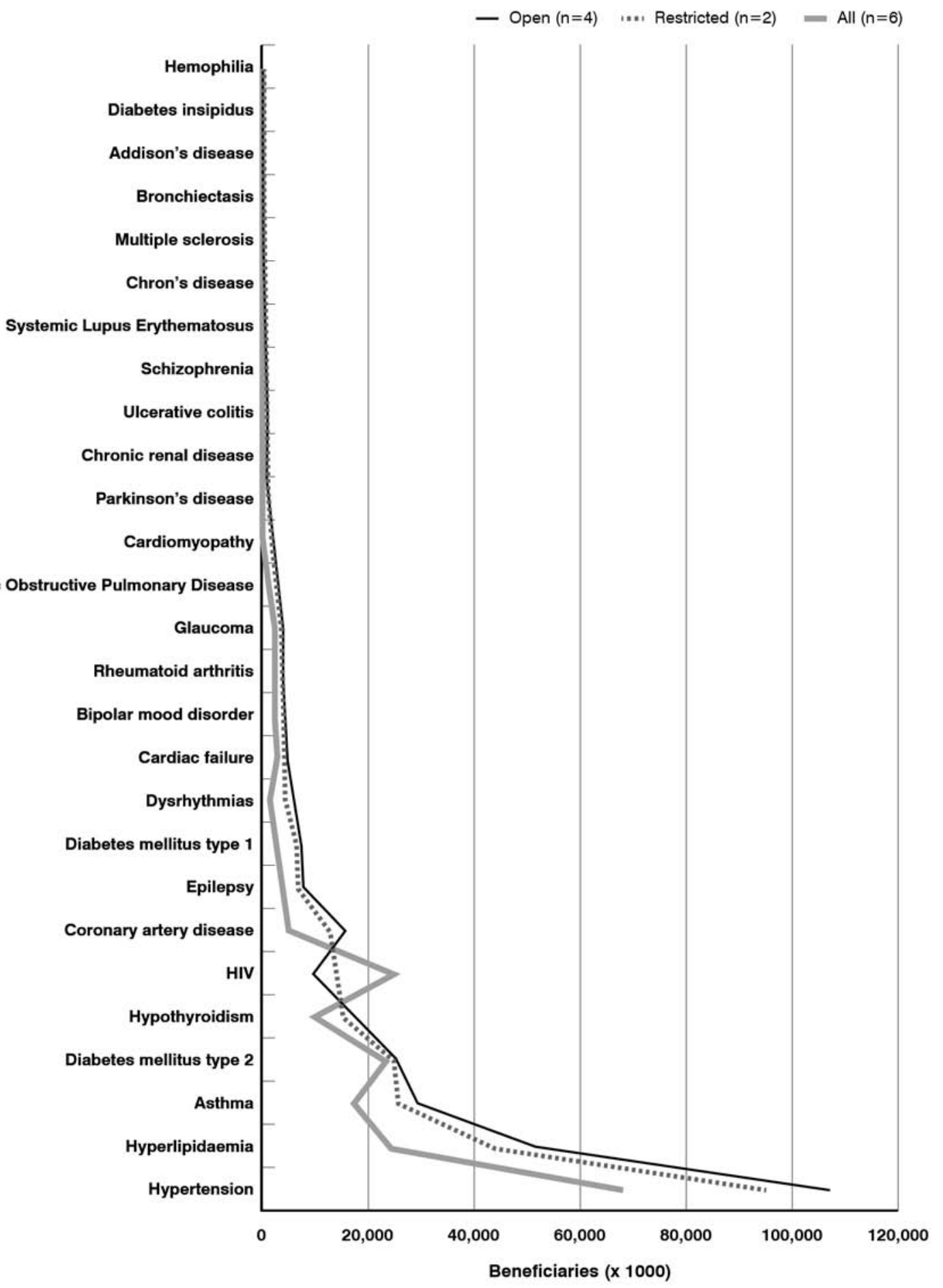

Figure 4. Prevalence of chronic conditions in schemes (per 1000 beneficiaries). Source: 2009 Annual Statutory Returns data CMS 


\begin{tabular}{lcc}
\hline \multicolumn{1}{c}{$\begin{array}{c}\text { Chronic conditions } \\
\text { per } \mathbf{1 , 0 0 0} \text { beneficiaries }\end{array}$} & Open schemes & Restricted schemes \\
\hline Hypertension & 106,227 & 67,503 \\
Hyperlipidemia & 51,349 & 23,974 \\
Asthma & 29,456 & 17,026 \\
Diabetes mellitus type 2 & 25,440 & 23,215 \\
HIV & 9,506 & 24,948 \\
Hypothyroidism & 17,618 & 9,783 \\
\hline
\end{tabular}

Table II. Chronic conditions per 1000 beneficiaries

in South Africa (MRC, 2011). Figure 4 shows prevalence of chronic conditions within the selected schemes. The chronic disease permeates several aspects of health service utilization and can be implicated in many diagnoses; therefore, all services for all relevant ICD-10 diagnostic codes were included. This provided a fair presentation of chronic disease health service use. For the purpose of this study, the prevalence of chronic disease was defined as every beneficiary who has any of the selected chronic conditions in a specific financial year (JanuaryDecember) was counted, and for beneficiaries with multiple conditions, each condition was counted separately. Table II provides an outline of the top six chronic conditions experienced by members of the sampled schemes.

It appeared that schemes are generally experiencing more non-communicable diseases with hypertension being high for both open and restricted schemes, whilst Figure 5 and Table II show that HIV/AIDS prevalence was relatively high for one restricted scheme compared to most schemes.

\section{Managed care and benefit option design}

Managing health care risk amongst other things includes efforts in controlling medical benefit costs. Such efforts require an emphasis in cost sharing and cost effectiveness analysis of various managed care models whilst conforming to the government's statutory requirements (provision of prescribed minimum benefit). Benefit option design therefore plays an important role in influencing health care utilization through a variety of ways including:

- The schemes choice of managed care model (i.e., pre-authorization system, patient channelling, discharge planning, use of GP networks, case management, designated service provider network (DSP), etc.).

- Benefit limits, co-payments and/or capping the number of visits.

- Use of formularies.

- Differences in reimbursement models for various components of the benefit package (i.e., payments at scheme's tariff rate, capitation agreements, etc.).

- Use of clinical protocols to manage utilization cost effectively.

This section provides a summary of key differences outlined by research participants as differentiating benefit option design within open and restricted schemes. Observations made in this study show that the benefit structure for open and restricted schemes is slightly different, reasons cited as influencing the difference include:

- Differences in the philosophy underpinning benefit option configuration.

- Impact of volatility of the health insurance market.

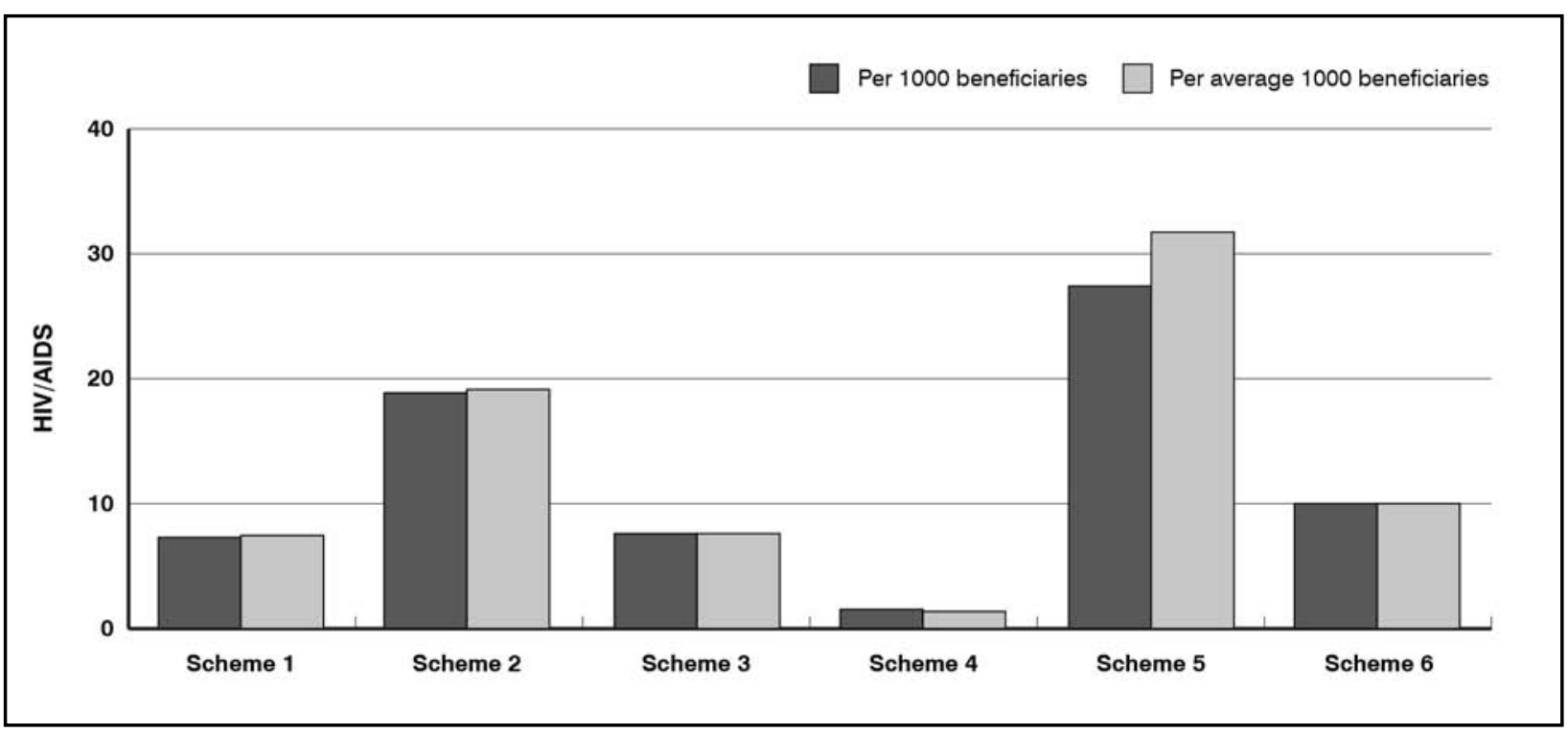

Figure 5. HIV/Aids prevalence per 1000 beneficiaries (2009). Source: 2009 Annual Statutory Returns data CMS 
- Uncertainty in determining premium rates (i.e. projections based on assumptions).

- Uncertainty and risks due to changes in the regulatory environment.

Table III provides a summary of key differences observed within the study relating to inhospital admission, MRI scans and medicine utilization. These observations were based on the review of all selected medical scheme rules; actuarial reports as well as feedback from responder validation meetings.

The utilization trend observed within this study as well as in Table III highlights key differences as well as the impact of each managed care model/protocol and benefit option rules in facilitating and/or monitoring utilization. The choice of one managed care model over the other often leads to tradeoffs whereby unintended consequences emanate. Furthermore, the effectiveness of each of the above program/s depends largely on each schemes and/or its internal administration's technical capacity, financial resources as well as technical rigor in utilization review and management.

\section{In-hospital admission}

As indicated earlier, utilisation of in-hospital services is often influenced by demographic factors, burden of disease including preva-

\begin{tabular}{|c|c|c|c|}
\hline Benefit design & $\begin{array}{l}\text { Open } \\
\text { schemes }\end{array}$ & $\begin{array}{l}\text { Restricted } \\
\text { schemes }\end{array}$ & Impact on utilization \\
\hline Facility based case managers & Yes * & - & $\begin{array}{l}\text { Better coordination of in-hospital patient care, discharge planning } \\
\text { and better health outcomes (i.e. low re-admission rate) }\end{array}$ \\
\hline $\begin{array}{l}\text { Benefit limits /co-payments } \\
\text { on MRI scans (excluding PMB } \\
\text { conditions) }\end{array}$ & Yes & - & $\begin{array}{l}\text { Schemes with unlimited access to MRI scans were observed to be } \\
\text { experiencing high utilisation when compared to schemes with some } \\
\text { benefit limits. For example, literature suggests that close to } 80 \% \text { of } \\
\text { back pain, knee pain or suspected cartilage tear do not require MRI } \\
\text { scan interventions therefore schemes should first determine clinical } \\
\text { necessity before granting access }\end{array}$ \\
\hline $\begin{array}{l}\text { Payments of MRI scans from } \\
\text { the medical savings account } \\
\text { /above threshold benefit } \\
\text { (excluding PMB conditions) }\end{array}$ & Yes ** & - & $\begin{array}{l}\text { Figure } 11 \text { illustrates the impact of paying MRI scans from the MSA/ } \\
\text { day to day benefits. Schemes have to manage trade-offs and } \\
\text { addressing overuse, some elements of "supply induced demand" } \\
\text { without denying their members access to required care }\end{array}$ \\
\hline $\begin{array}{l}\text { Use of brand medicine } \\
\text { vs. generic medicine }\end{array}$ & Yes & - & $\begin{array}{l}\text { All the restricted schemes appear to have been able to channel their } \\
\text { patients towards use of generic medicine opposed to } 3 \text { of } 4 \text { open } \\
\text { schemes (Figure 14) }\end{array}$ \\
\hline
\end{tabular}

Table III. Benefit option design and impact on utilisation. Note: MRI scan utilization included in-hospital and out-of hospital care as well as Prescribed Minimum Benefits (PMB) and non PMB conditions

* Only one out of 3 open schemes sated that they were using facility based case managers within some of their networks

** Out of the four open schemes who participated in this project 3 schemes pay MRI scans from the medical savings account/ATB within certain benefit options

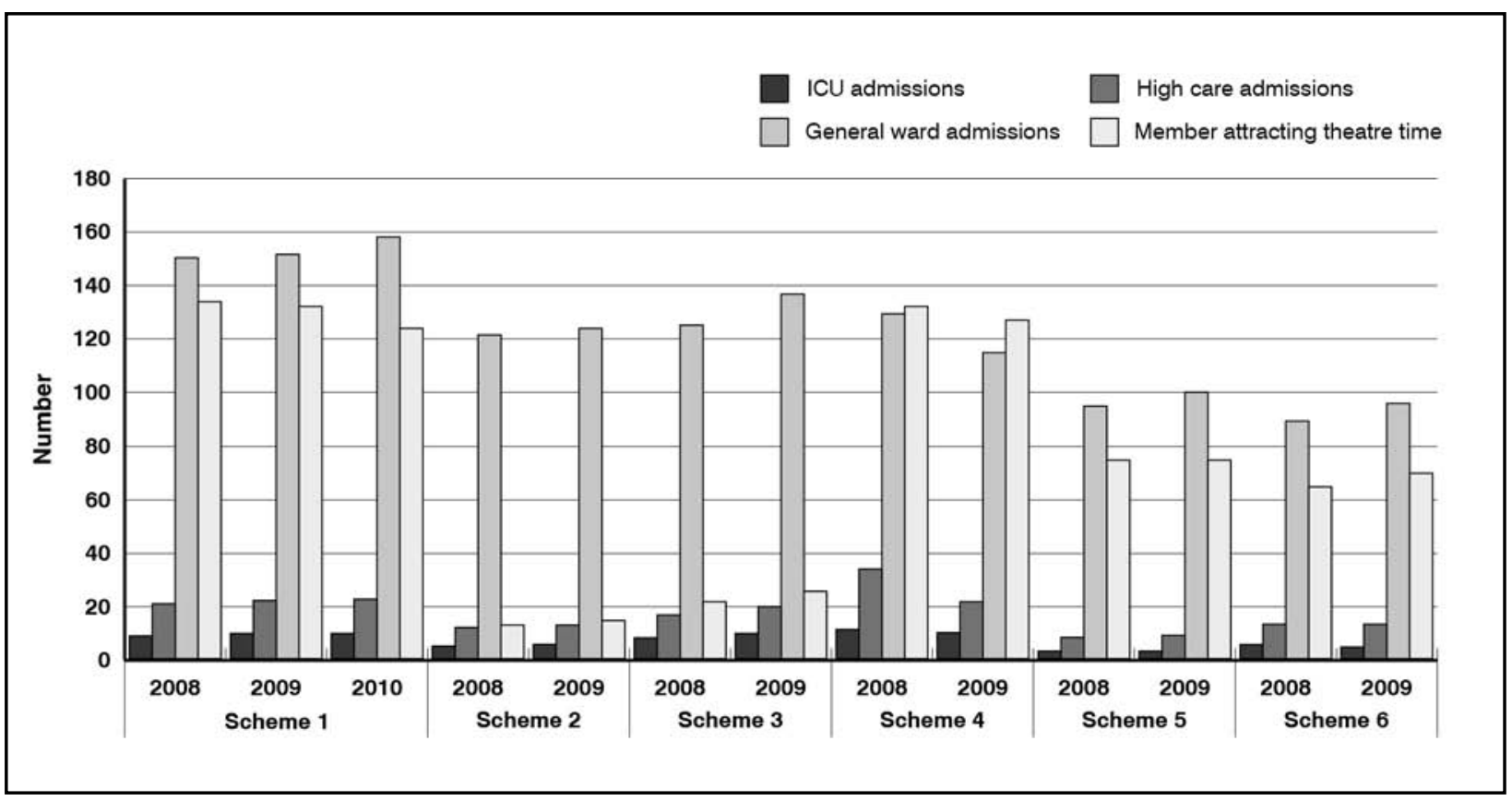

Figure 6. Number of admissions stratified by hospital admission facility 
lence of HIV pandemic and improvements in medical technology as well as managed care interventions. Between 2008 and 2010 private hospital expenditure - which includes ward fees, theatre fees, consumables, medicines and per diem arrangements - consumed between $40.5 \%$ and $40.9 \%$ of the total benefits paid by medical schemes from the risk pool, whilst total hospital benefits paid from the medical savings accounts ranged between $1.5 \%$ and $2.1 \%$. In addition, in-hospital managed care arrangement fees ranged between $1.8 \%$ and $2.8 \%$ for the equivalent years [9]. This section provides an outline of in-hospital utilisation trends with a specific focus on total admissions stratified by departmental type, average length of stay, re-admission rate, as well as the total number of day cases.

\section{Total admissions: hospital units/departments}

Critical care is widely recognized as being both expensive and increasing within South Africa and internationally. This section reviews patient flow between general ward, ICU and high care within a hospital. Figure 6 provides an outline of the total number of admitted cases within each hospital department. As can be observed, $87 \%$ of the admitted cases were in the general ward compared to $13 \%$ and $1 \%$ of High Care and ICU. Only 2 schemes experienced more cases attracting theatre admissions compared to all other schemes. Also noted in Figure 6 is that scheme 2 and 3 reported significantly lower number on theatre admissions.

\section{Average length of stay}

The average length of stay (ALOS) measures how much time patients spend in hospitals.
This is a proxy measure for quality of care as well as efficiency within hospitals. In most cases a persistently high ALOS might mean that patients are being kept in hospital for too long therefore indicating inefficiency. Interpretation of this indicator should take into account case mix as well as exclusion of long term care, day cases and all ambulatory visits from the calculation. For the purpose of the study ALOS was defined as discharge date admission date, where admission and discharge on the same day were thus viewed as LOS $=0$. Results presented in this section excluded all of the above cases but due to unavailability of disaggregated data researchers were unable to do a case mix adjustment.

Figure 7 shows that restricted schemes have a relatively high ALOS compared to open schemes with a range between 2.6 and 3.7. When one compares the industry average as published by CMS for 2008/2009/2010 the ALOS range was between 3.7 and 6.2 , which is relatively higher than the observed trend. Also, when comparing ALOS with Figure 5 it was observed that one key contributing factor to the high ALOS for restricted schemes can be attributed to high prevalence of HIV/AIDS.

Figure 7 also illustrates that some open schemes are able to contain ALOS to remain within same levels over a period of time (i.e., scheme 1, scheme 2 and scheme 3) whilst others have experienced variable distribution.

\section{Re-admission}

Re-admission to a hospital shortly after discharge may be viewed as an adverse outcome of care. This indicator is useful for monitoring quality and it can also be used to identify pro-

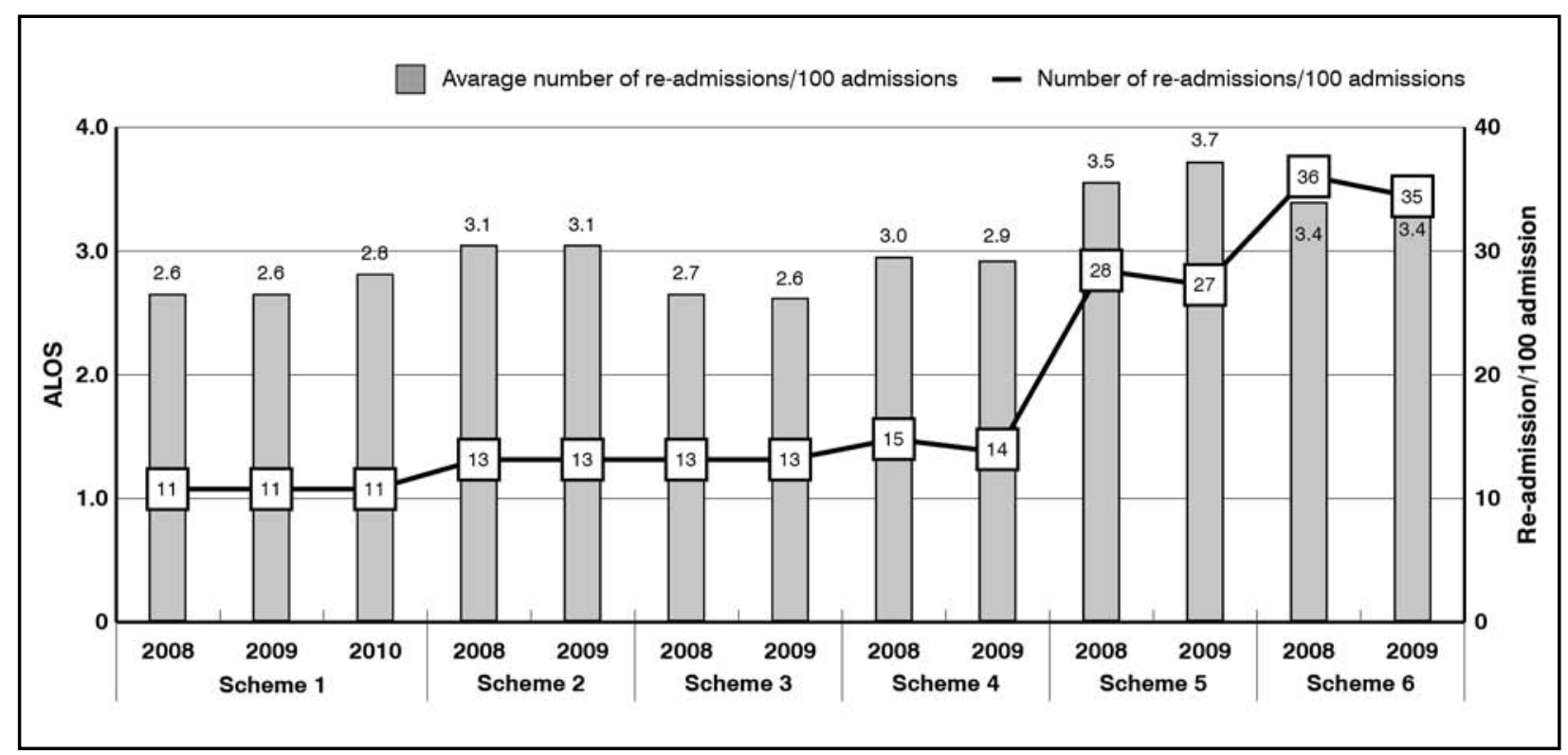

Figure 7. Average length of stay 
viders whose quality of care may be inferior, so that appropriate corrective measures may be undertaken [10]. For the purpose of the study, re-admission rate is defined as re-admissions within 28 days, where count of admissions for same beneficiary where admission_date(2) discharge_date $(1)<29$ days.

Effectiveness of discharge planning may reduce the length of hospital stay, and in some cases may reduce re-admissions also, case managers within managed care programmes often play a critical role in this regard. A thorough analysis and interpretation of this indicator should include adjusting data to cater for disease severity, complexity of cases, hospital type (public and/or private), planned sequence of care, age and gender differentiation if patient level data are available. Even though re- sults presented below were not adjusted for all the above factors, a correlation of average age and pensioner ratio was undertaken. Figures 7 and 8 show the distribution of re-admission rate across all selected schemes, with a range between $11 \%$ and $36 \%$ compared to average age and pensioner ratio. It appeared that restricted schemes experienced high re-admission rates compared to open schemes; this observation is relatively more than the observation made within open schemes whilst the average age and pensioner ratio for both schemes is relatively low when compared to other schemes. This trend also correlates well with the ALOS presented above.

\section{Same day admissions}

This indicator is an estimate of the potential cost savings that could be achieved if

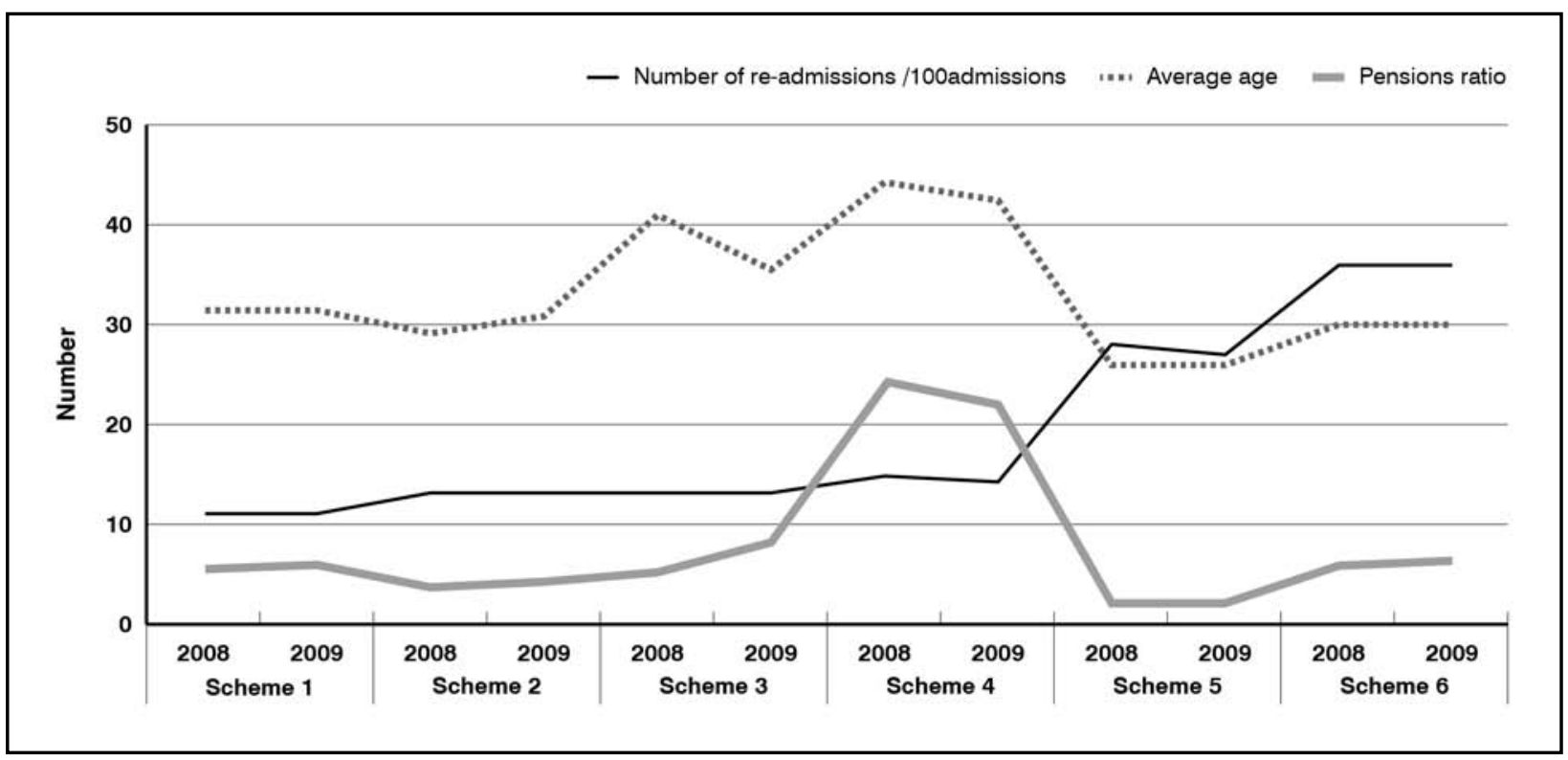

Figure 8. Re-admission rate, average age and pensioner ratio

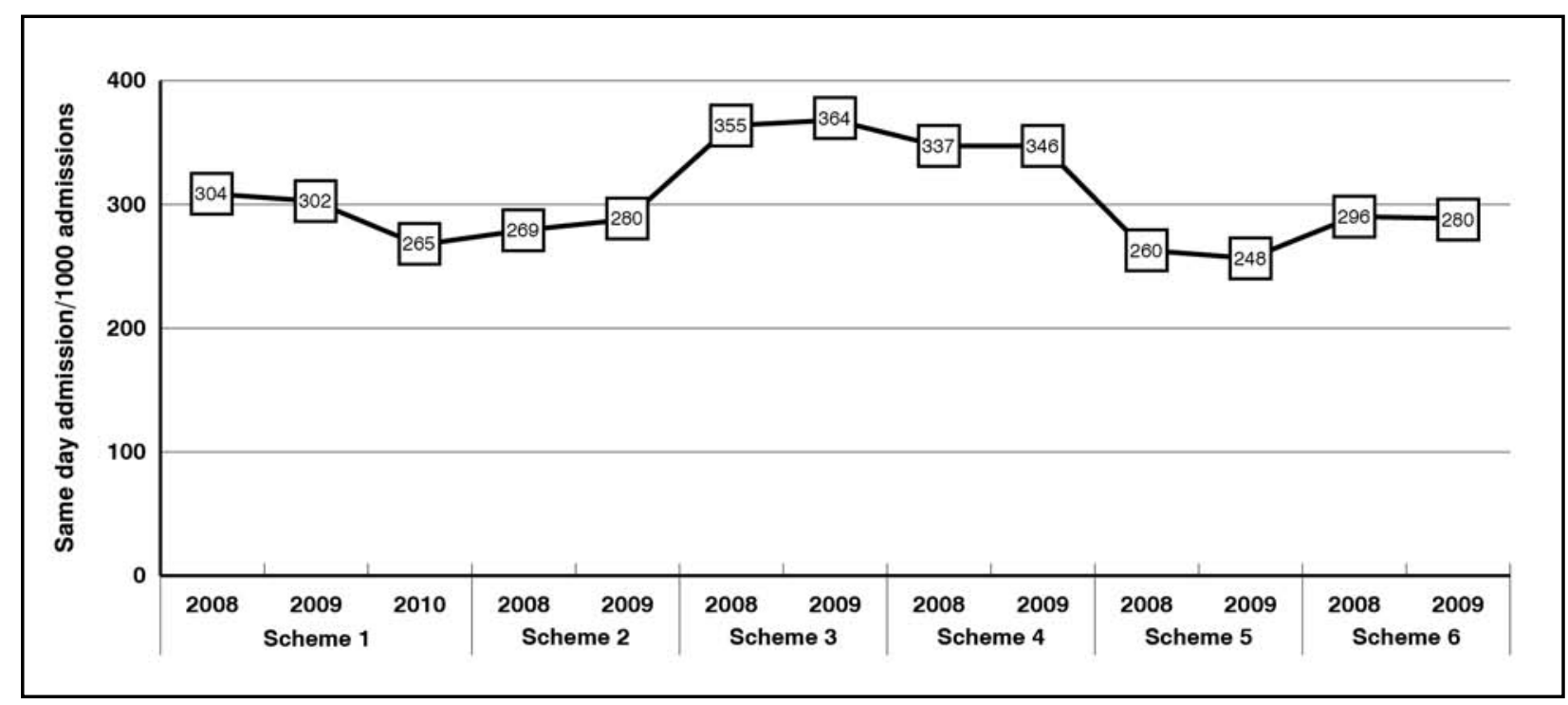

Figure 9. Same day cases per 1000 admissions 
relevant specialists achieved a high rate of day-case as opposed to in-hospital admitted cases. For the purpose of this study same day admissions was defined as a count admissions with $\operatorname{LOS}=0$. For this indicator to give accurate picture, procedures which can be carried out safely as a day case need to be comprehensively defined. Figure 9 shows an outline of day cases per 1000 admissions. As can be observed, the distribution of day cases range between a minimum of 248 cases per 1000 admissions and a maximum of 364 cases with an average of 300 cases. Scheme 3 and 4 appeared to have the highest number of day cases when compared to other schemes whilst their average age for both years is high.

\section{Medicine expenditure}

According to a study undertaken by Andersen et al., evidence on medicine expenditure shows that up to $90 \%$ of the population in developing countries purchase medicines through out-of-pocket payments, making medicines one of the largest family expenditure after food [5]. Cameron also contends that over time medicines have become unaffordable for a large section of the population and can be a major burden on patients and a barrier towards access to health care [11].

South Africa shares the context as outlined above. The implementation of Single Exit Price (SEP) in 2004 lead to a $19-21 \%$ cost savings on medicine expenditure [12]. From 2007 the gains through SEP regulation started to wear away, the Council for Medical Schemes noticed an increase in medicine expenditure whereby medicine become the third highest cost driver in private health care [9]. This study undertook an analysis on medicine expenditure within the context of exploring the effectiveness of medical schemes in medicine utilisation review and management. Figure 10 shows an outline of chronic, acute and oncology expenditure across all selected schemes. As can be observed, average expenditure on acute medicine is higher than chronic medicine and oncology. This is an undesired observation since chronic medicine can be expensive and when chronic patients are enrolled in chronic disease program schemes can prevent unnecessary complications leading to in-hospital admission.

As above mentioned, formularies and protocols are part of managed cared interventions used to promote cost-effective use of medicines. Usually medicine included within the schemes formulary is covered in full without out-of pocket payment and for most schemes, medicines on the formulary list will include generics.

Member utilisation of the schemes formulary depends on the following factors:

- member's knowledge of their entitlements;

- benefit option purchased (some options cover medicine costs in full);

- co-payments;

- scheme rules;

- if the condition being treated is a Prescribed Minimum Benefit condition or not.

Figure 11 shows that most schemes appear to be spending more on formulary medicine compared to non-formulary. Ideally, where appropriate, all schemes should channelling

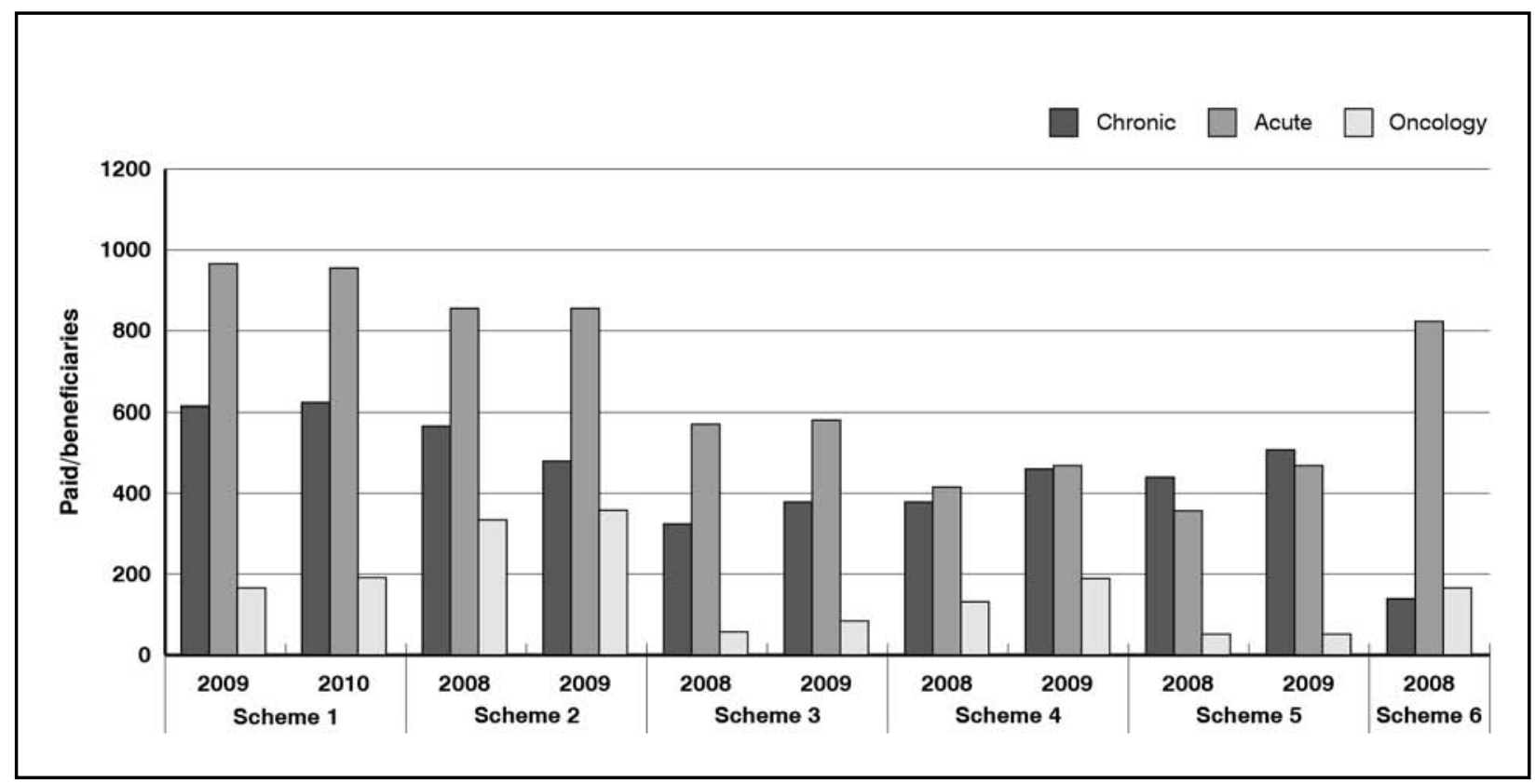

Figure 10. Chronic, Acute and Oncology expenditure 
their members towards use of generic medicine as per the Medicines and Related Substances Control Act which mandates: «Pharmacists to offer patients a generic substitute for any medicine prescribed, unless the prescribing doctor explicitly states that the medicine should not be substituted».

Furthermore, since the implementation of the Medicines and Related Substances Control Act in 1997 [13], there has been an increased use of generic medicines between 2003 until recently by some medical schemes. This study noted with concern that in spite of this regulatory intervention, only 2 schemes were able channel their members towards use of generics for both 2008 and 2009 (Figure 12). Especially since most brand medicine tend to attract co-payments (depending on the benefit option). As such, the Council for Medical Schemes has observed an increased incidence of co-payments highlighting the discrepancy between amounts charged by providers and what medical schemes are prepared to pay. This trend has been evidenced through the increase in the use of medical savings accounts which, in most cases, leads to members exhausting their benefits before the end of the financial year.

\section{DISCUSSION}

Data presented in this paper provide an overview on how schemes are managing utilisation for selected private health care services.

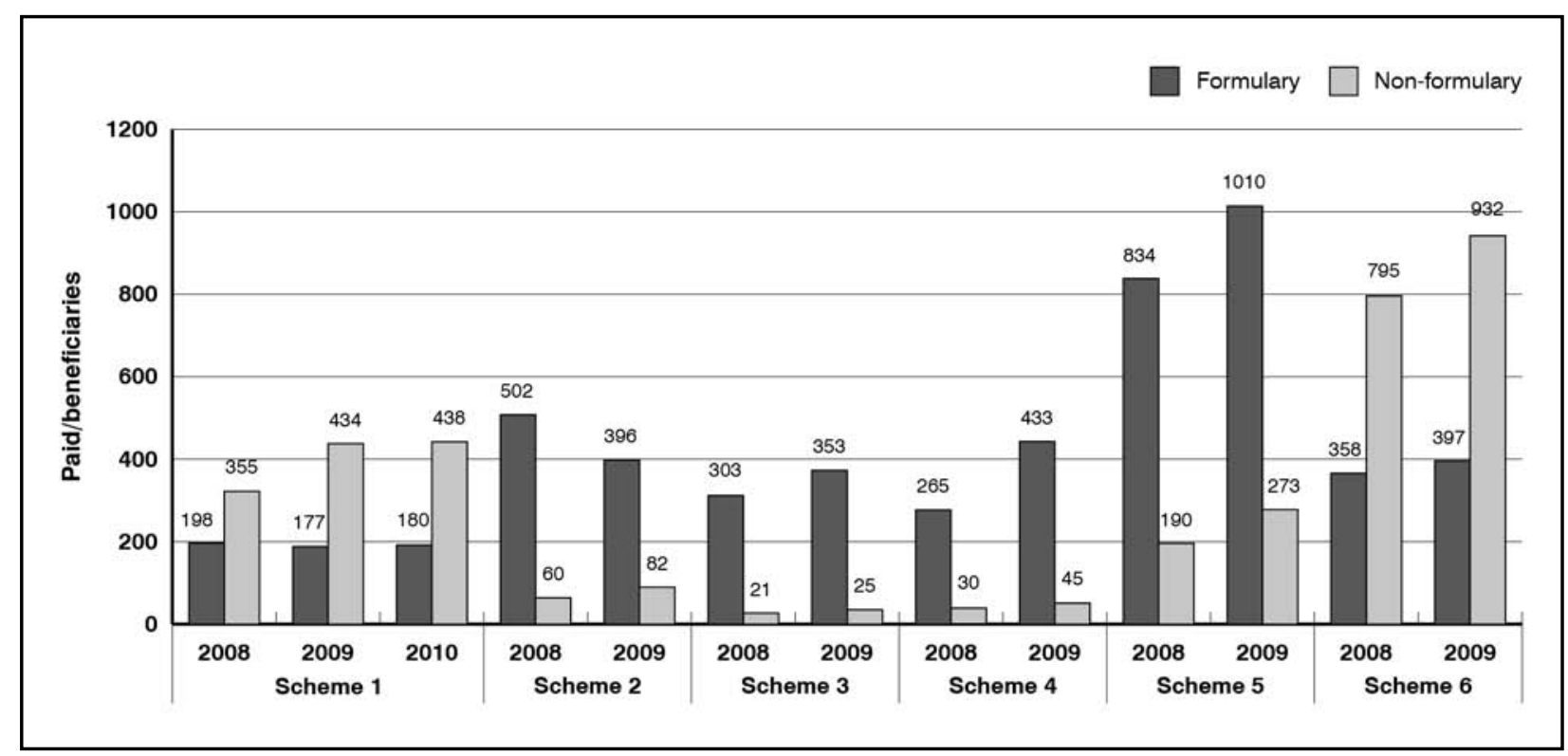

Figure 11. Formulary and Non formulary expenditure

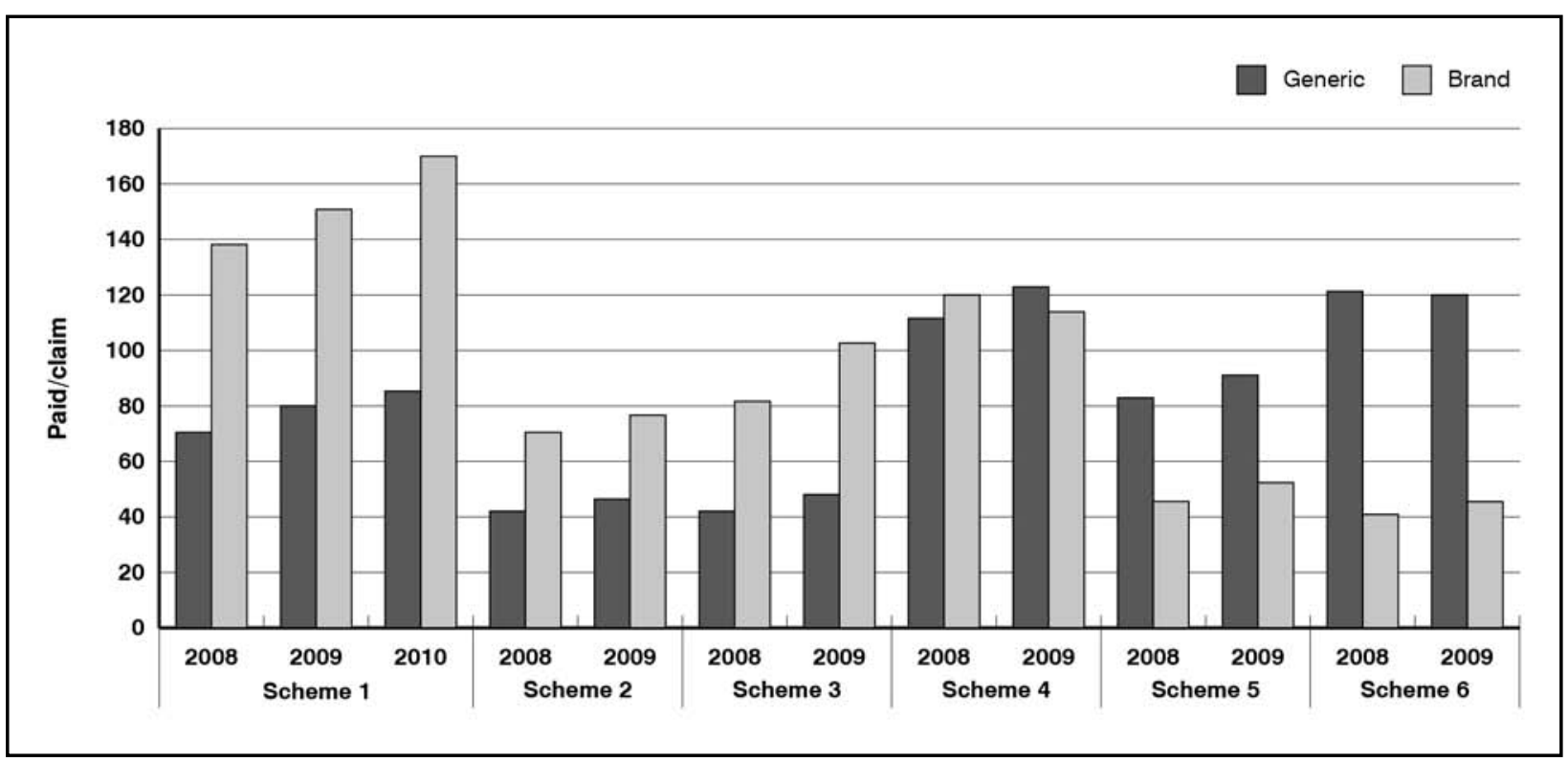

Figure 12. Generic and Brand Medicine expenditure 
This study also highlights particular areas within which medical schemes can improve and contain hospital admission. Whilst acknowledged that hospital admissions including length of stay and re-admission rates are complex indicators which requiring data to be adjusted for clinical factors such as type of diagnosis, disease severity, complexity of the case/condition being treated, hospital type and size (private/public hospitals), this paper shows the importance of effective managed care programs including effective use of case managers. Dieterich et al. concur by also suggesting that «one strategy for dealing with avoidable re-admissions is for case managers to interview all re-admitted patients to gain an understanding on why re-admission occurred as well as undertake a review of patient's clinical record to establish causality» [14].

Whilst Dieterich's recommendation might be ideal, it is acknowledged that not all medical schemes will have resources to employ on-site facility managers. It is therefore recommended that medical schemes should identify low resource and easy to implement best practise guidelines for prevention of avoidable hospital admissions such as: review of characteristics and processes along the care continuum, profiling of providers, discharge planning, care coordination, patient education on self-administration of medication and effects of medicine mismanagement, home health care after discharge, use of step-down facilities where applicable.

The most effective way of controlling health care costs also includes the scope of benefits provided, including associated costs but also to manage the appropriateness of utilization and influence the price paid to providers. All these objectives underlie benefit option design of managed care plans/programs. Benefit limits are one such intervention and have always been used within the South African medical schemes industry; however such limits often have a potential of exposing medical schemes members to substantial outof-pocket costs thereby infringing on equity consideration whilst in extreme cases, benefit limits may give members the impression of entitlement which is expected to be used regardless of the health care need. Although in most cases members who are in need of cover are likely going to be the ones exhausting their benefits therefore effective managed care programs including continuous assessment of benefit limits as well as an analysis of the impact of such limits to members and clinical necessity should always be reviewed.

\section{PROJECT CHALLENGES}

The following are key challenges encountered within the research project:

- Use of aggregated data as opposed to disaggregated data.

- Not all schemes were able to categorize total hospital admissions by Diagnosisrelated Groups (DRGs).

- Medical schemes and administrators also have different perspectives on the definition and computation of health care utilisation measures.

- Use of different Information Technology Systems to capture and interpret beneficiary information.

- There are also limited surveys on private health care utilisation measures as well as industry norms and standards.

- Some stakeholders only captured primary ICD10 codes as opposed to both primary and secondary ICD10 codes.

- There is limited access to patient's clinical notes from the providers.

- Project did not include option level analysis in order to explore impact of changes in demographic profile on utilisation.

- There aer differences in risk adjustment methodology by different stakeholders.

Most of these challenges were addressed in the piloting exercises which lead to the development and finalisation of the data specification as well as the responder validation exercise which facilitated consultation with the medical schemes and administrators.

\section{CONCLUSION}

Since benefit option design is one of the key factors influencing the outlined utilisation trends, medical schemes should cautiously manage trade-offs between cost savings interventions and barriers to appropriate care. Such trade-offs should always seek encourage equity, health outcomes and quality. Medical schemes can evaluate such programs continuously to ensure that they are highly responsive to each members needs.

In order to manage escalation of costs where possible medical schemes should continually channel their patients towards appropriate level of care in order to avoid out-of-pocket payments by members.

Medical schemes should also educate their members on their benefit entitlements and responsibilities along with associated benefit limits.

Data presented in this paper provide a valuable foundation for further research within private health care specifically, within the area of benefit option design addressing issues around 
cost escalation; value based managed care interventions, financial protect of members and unpacking medicine expenditure trends linking observations to the risk profile of the scheme along with prevalence of disease.

\section{ACKNOWLEDGEMENTS}

The authors would like to thank the six large medical schemes along with the administrators who participated in this research project. Their input and comments were valuable in contextualising observations as well as drawing conclusions. We would also like to convey our gratitude to Thulani Matsebula for providing support to the research team as well as Ronelle Smit, Nkuli Mlaba and Selaelo Mametja for the clinical opinions provided in the definition of hospital indicators.

\section{PRIOR/DUPLICATE PUBLICATION}

An earlier version of this manuscript including an analysis of other utilisation indicators excluded in this paper (such as utilisation of MRI scans) has been published through industry circular by the Council for Medical Schemes in a form of a working paper. This manuscript has not been published in any scientific journal.

\section{REFERENCES}

1. National Treasury. Downloaded from Vulindlela database, May 2011

2. Blecher M, Kollipara A, DeJager P, et al. South African Health Review, Health Systems Trust, 2011

3. Council for Medical Schemes. Health Care Utilisation study, 2011. A Working Report

4. Statistics South Africa, Consumer Price Index, 2008-2010

5. Andersen RM. Revisiting the behavioural model and access to medical care: does it matter? J Health Soc Behav 1995; 36: 1-10

6. Hausmann-Muela S, Ribera JM, Nyamongo I. Health-seeking behaviour and the health system response. DCPP Working Paper No. 14, 2003

7. Machin D, Campbell MJ. Statistical tables for the design of clinical trials. Oxford: Blackwell Scientific Publications, 1987

8. Medical Research Council 2011

9. Council for Medical Schemes Annual Reports 2008-2010

10. Marshall M, Crowther R, Sledge WH, et al. Day hospital versus admission for acute psychiatric disorders. Cochrane Database Syst Rev 2011; (12): CD004026

11. Cameron ME, Ross-Degnan D, Ball D, et al. Medicine prices, availability, and affordability in developing and middle-income countries: a secondary analysis. The Lancet 2008; 373: 240-9

12. Council for Medical Schemes Annual 2004-2007

13. Medicines and Related Substances Control Act 90, 1997

14. Dieterich M, Irving CB, Park B, et al. Design should help use of patients' data. Cochrane Database Syst Rev 2010; (10): CD007906

\section{GENERAL REFERENCES AND SUGGESTIONS FOR FURTHER READINGS}

- Btesh S. International research in the organization of Medical Care. Medical Care 2010; 3: 41-46987

- Buck D, Godfrey C, Morgan A. Performance Measures and Health Promotion Targets. Centre for Health Economics, York University 1996

- Campbell S M, Braspenning J, Hutchinson A, et al. Research methods used in developing and applying quality indicators. Qual Saf Health Care 2002; 11: 358-64

- Campbell SM, Roland MO, Buetow SA. Defining quality of care. Social Science and Medicine 2000; 51: 1611-25

- Campbell SM, Sweeney GM. The role of clinical governance as a strategy for quality improvement in primary health care. Br J Gen Pract 2002; 19: 257-63

- Council for Medical Schemes. Draft Report on Minimum Datasets, 2008

- Dias FS, Severo M, Barros H. Determinants of Health care utilization in Portugal. BMC Health Services Research 2008; 8: 207

- Ibrahim JE. Performance indicators from all perspectives [editorial]. Int J Qual Health Care 2001; 13: 431-2. doi: 10.1093/intqhc/13.6.431 
- Felee C. Objective trends and Perceptions of Health status in Germany. ENEPRI 2006. Research Report No. 21

- Guy D, Lorens A, Helmchen R, et al. Does Advanced Medical Technology Encourage Hospitalist use and their Direct Employment by Hospitals? Health Econ 2009; 18: 237-47

- Hospital Association of South Africa. Private Hospital Review, 2009

- Heuvel WJA, Wieringh R, Heuvel LPM. Utilization of Medical Technology assessment in Health Policy. Health Policy 1997; 42: 211-32

- Jacobs R, Smith P, Goddard M. Measuring Performance: An examination of composite performance indicators. Centre for Health Economics 2004, Technical Paper Series 29

- Jones J, Hunter D. Consensus Methods for medical and health services research. BMJ 1995; 311: 376-80

- Jun JB, Jacobson SH, Swisher JR. Application of Discrete-event simulation in health care clinics: A survey. J Oper Res Soc 1999; 50: 109-23

- Mcgynn E. The outcomes utility index: will outcomes data tell us what we want to know? International Society for Quality in health care 1998; 6: 485-90

- Morgan M, Beech R. Variations in length of stay and rates of day case surgery: implications for the efficiency for Surgical Management. J Epidemiol Community Health 1990; 44: 90-105

- Morgan s, Hurley J. Influence on the health Care Technology Cost-Driver. Commission on the Future of Health Care in Canada, 2002. Discussion paper Number 14

- National Department of Health, Chapter 5: Minimum Standards in Health Services 1995, South Africa

- National Treasury, Social security and national health insurance. 2012, South Africa

- Purohit B, Siddiqui TA. Utilization of Health Services in India. Economic and Political. Weekly 1994; 29: 1071-80

- Performance assessment framework. Quality and Performance in the NHS: Clinical Outcomes, 1999. Public health Development Unit NHS

- Randhawa J, Riley R. Trends in Hospital Utilization, 1982-83 TO 1992-93. Health Reports 1995; 7: 1

- South African Health Review 2011

- Sox H, Owens D, Abrams HL. Assessment of Diagnostic Technology in Health Care: Rationale, Methods, Problems, and directions. Institute of Medicine. Council on Health Care Technology, 1989

- Thomas W J, Holloway JJ. Investigating Early Readmission as an Indicator for Quality of Care Studies. Medical Care 1991; 29: 4

- The NHS Performance Assessment Framework, 1999. Catalogue Number: 16431

- Wyatt JC, Wright P. Design should help use of patients' data. Lancet 1998; 352: 1375-8

- Xu J, Wang W, Li Y, et al. Analysis of factors influencing outpatient workload at Chinese health centres. $B M C$ Health Services Research 2010; 10: 151

- Centre for Actuarial research (CARE): Chronic Medicine Benefits in Medical Schemes, Monograph No. 7 ISBN 0-7992 